p-ISSN: 1411-4348, e-ISSN: 2541-4577

\title{
ANALISIS PENGARUH PEMBAKARAN BRIKET CAMPURAN AMPAS TEBU DAN SEKAM PADI DENGAN MEMBANDINGKAN PEMBAKARAN BRIKET MASING-MASING BIOMASS
}

\author{
Tri Tjahjono, Abidin Rachman, Subroto \\ Jurusan Teknik Mesin Fakultas Teknik Universitas Muhammadiyah Surakarta \\ Jl. A.Yani Tromol PosI Pabelan Surakarta \\ email:tri_tjahjono@ums.ac.id
}

\begin{abstract}
ABSTRAK
Dewasa ini, harga bahan bakar semakin mahal dan tingkat pemakaian bahan bakar minyak bumi semakin meningkat, hal ini sudah terlihat pada fenomena yang terjadi dimana pengambilan minyak bumi yang dilakukan terus menerus yang mengakibatkan tipisnya cadangan minyak bumi yang ada. Oleh kerena itu timbul pemikiran untuk membuat bahan bakar alternatif yang berasal dari campuran batubara dan sampah pertanian (ampas tebu dan sekam padi).

Penelitian ini meneliti laju pembakaran pada bahan bakar padat, yaitu : pembakaran briket campuran batubara, ampas tebu dan sekam padi dengan membandingkan pembakaran briket masing- masing biomass dengan perbandingan campuran $50 \%$ batubara: $50 \%$ Biomass, dengan kecepatan udara $0,3 \mathrm{~m} / \mathrm{s}$.

Dari penelitian didapatkan bahwa laju pembakaran briket tertinggi adalah pada pembakaran ampas tebu. Sedang penambahan ampas tebu kedalam sekam padi akan memperbaiki peforma pembakaran dari sekam, dimana sekam padi mempunyai pembakaran yang rendah, juga pencampuran kedua biomass tersebut akan memperbaiki polusi yang ditimbulkan.
\end{abstract}

Kata kunci : Batubara, Ampas tebu, Sekam padi, laju pembakaran

\begin{abstract}
Nowadays, the price of fuel is more expensive and the level of use of petroleum fuels increases, it is already seen in the phenomenon that occurs where petroleum extraction is done continuously resulting in the thinness of existing petroleum reserves, therefore thought arises to make alternative fuels derived from a mixture of coal and agricultural waste (bagasse and rice husks).

This study examined the combustion rate of solid fuels, namely: combustion of coal mixture briquettes, bagasse and rice husk by comparing the combustion of each briquettes biomass with 50\% mixture ratio of coal: 50\% Biomass, with air velocity $0.3 \mathrm{~m} / \mathrm{s}$.

It was found that the highest briquette combustion rate was at burning bagasse. Adding bagasse to rice husk will improve the burning performance of the husk, where the rice husk has low combustion, also mixing the two biomass will decrease the pollution..
\end{abstract}

Keywords: Coal, bagasse, rice husk, burning rate. 


\section{PENDAHULUAN}

Berbagai penelitian telah dilakukan untuk menganalisa karakteristik pembakaran pada biobriket, yang mana dilakukan sebagai tolak ukur untuk pembuatan bahan bakar dari bahan yang mudah didapat dan efisien dalam penggunaanya. Dalam penelitian ini digunakan sampel sekam padi dan ampas tebu dikarenakan murahnya dana untuk menyiapkan bahan mentahnya serta dapat memanfaatkan batu bara yang berkualitas rendah menjadi bahan bakar yang berkualitas tinggi. Dalam penelitian ini akan dibuat briket dengan tiga jenis yang berbeda yaitu briket campuran 50\% batubara dengan 50\% sekam padi, 50\% batubara dengan 50\% ampas tebu dan 50\% batubara dengan $25 \%$ sekam padi dan $25 \%$ ampas tebu, yang digunakan untuk meneliti karakteristik pembakaran Biobriket tersebut dan mengetahui seberapa besar kandungan polutannya.

\section{BATASAN MASALAH}

Untuk menghindari melebarnya masalah, maka perlu adanya pembatasan masalah sebagai berikut:

Dalam penelitian ini masalah yang diteliti adalah Laju pengurangan massa, laju pembakaran dan temperatur Biobriket dalam proses pembakaran serta kandungan polutan yang ditimbulkannya.

\section{TUJUAN PENELITIAN}

1. Mengolah sampah pertanian, yang selama ini kurang termanfaatkan menjadi bahan bakar alternatif.

2. Memanfaatkan batubara yang banyak terdapat di Indonesia sebagai bahan bakar yang lebih baik.

3. Menentukan karakter pembakaran biobriket, termasuk dalam hal polusi yang mungkin ditimbulkan.

\section{DASAR TEORI}

\section{Pembakaran Bahan Bakar Padat.}

Pembakaran bahan bakar padat melalui tahapan-tahapan tertentu, tahapan-tahapan tersebut adalah sebagai berikut :

1. Pengeringan

Tahap awal yang terjadi dari proses pembakaran bahan bakar padat adalah pengeringan, yaitu suatu proses dimana ketika suatu partikel dipanaskan dengan dikenai temperatur tinggi atau radiasi api, air dalam bentuk moisture di permukaan bahan bakar tersebut akan menguap, sedangkan yang berada didalam bahan bakar akan mengalir keluar melalui pori-pori partikel dan menguap.

2. Devolatilisasi

Yaitu proses bahan bakar mulai mengalami dekomposisi setelah terjadi pengeringan. Proses dekomposisi merupakan peristiwa pecahnya ikatan kimia secara termal dan volatile matter (yang merupakan hasil proses devolatilisasi) keluar dari partikel

\section{Faktor-faktor yang mempengaruhi pembakaran bahan bakar padat:}

1. Ukuran partikel

Waktu reaksi partikel tergantung pada diameter awalnya. Partikel yang lebih kecil ukurannya akan lebih cepat terbakar. Regland dan Yang, 1985( Dwi Aries. 2003 )

2. Kecepatan aliran udara

Penelitian dari Tri Istanto (2003) menunjukkan bahwa laju pembakaran batubra dan sampah akan naik dengan adanya kenaikan kecepatan aliran udara dan kenaikan 
temperatur, hasil yang sama juga didapatkan dalam peneliatian oleh Bateman et al (1995),Ragland dan Yang (1985).( Dwi Aries, 2003 )

3. Temperatur udara pembakaran

Pengaruh temperatur terhadap waktu pembakaran partikel berukuran mm telah diteliti oleh Bateman et al (1995), ( Dwi Aries, 2003 ), dimana waktu pembakaran akan berkurang dengan adanya kenaikan temperatur udara pembakaran. Hasil yang serupa didapat juga oleh Ragland dan Yang (1985), ( Dwi Aries, 2003 ) serta Tri Istanto, (2003)

\section{METODE PENELITIAN}

Untuk memudahkan jalannya penelitian, maka dibuat suatu alur penelitian yang dapat dilihat pada gambar berikut:

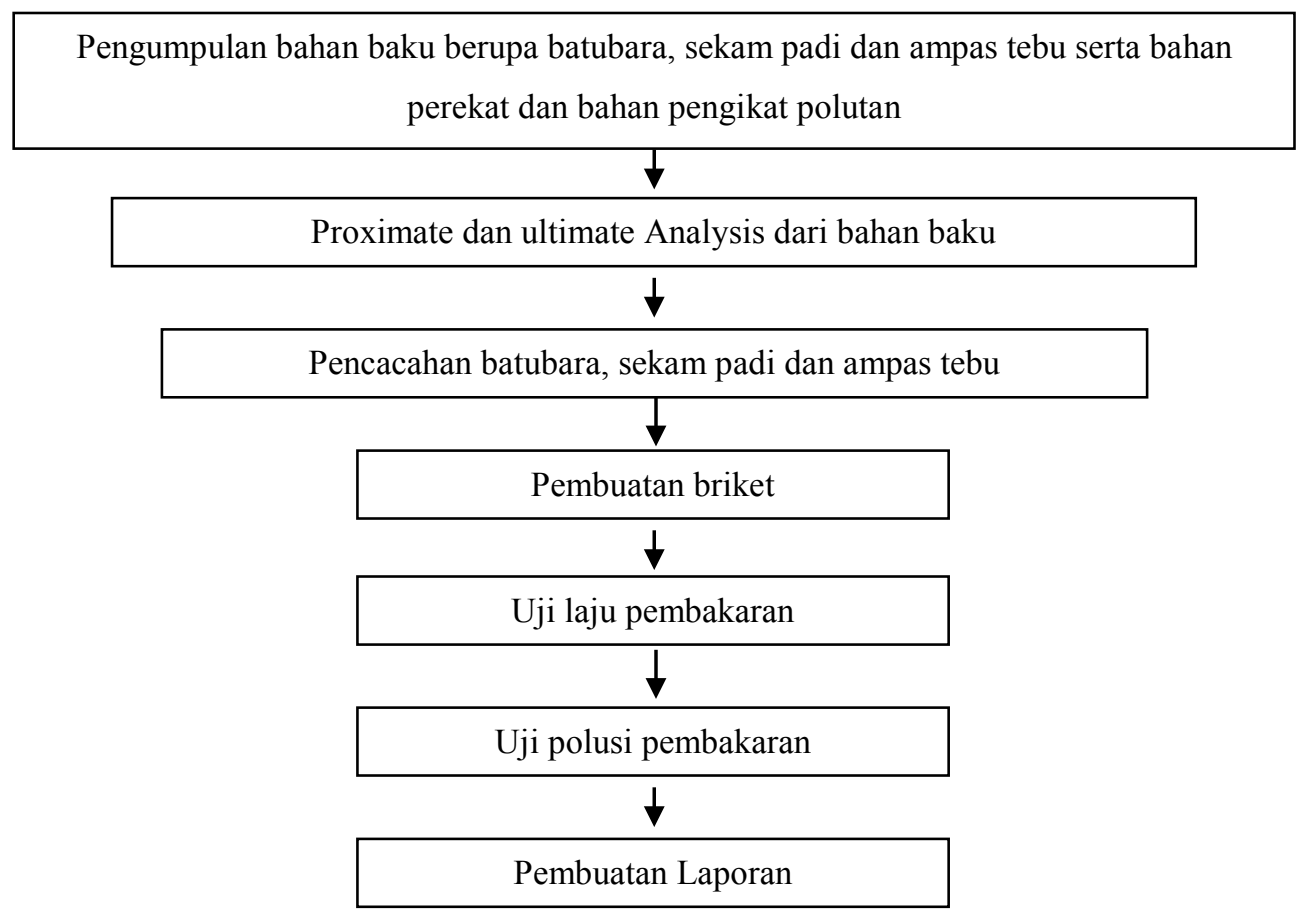

Gambar 1. Flowchart penelitian

\section{Pengumpulan Bahan Baku}

Bahan-bahan yang digunakan dalam penelitian ini adalah :

a. Batubara yang ada di sekitar Surakarta.

b. Ampas tebu yang di dapat dari PG Gondang Klaten.

c. Sekam padi yang yang banyak terdapat di sekitar kita yang kurang termanfaatkan.

d. Tepung kanji dan air sebagai bahan pengikat bahan biobriket, serta gamping untuk pengikat polutannya.

e. Gas LPG, sebagai pemanas tungku.

\section{Peralatan Yang Digunakan}

Peralatan utama yang digunakan dalam penelitian adalah alat pengepres briket. Alat ini dibuat dengan cara memodifikasi dongkrak hidrolik yang dipasang manometer yang berfungsi untuk mengetahui besarnya tekanan yang terjadi dalam dongkrak tersebut.

Disamping itu juga peneliti menggunakan alat pembakaran yang terdapat di Laboratorium Teknik Mesin Universitas Gajah Mada.. 
Adapun Komposisi dan Variasi jenisnya sebagai berikut :

a. $50 \%$ Batubara dan $50 \%$ Sekam padi

b. $50 \%$ Batubara dan 50\% Ampas tebu.

c. $50 \%$ Batubara, $25 \%$ Sekam padi dan $25 \%$ Ampas tebu.

\section{HASIL PENELITIAN DAN KESIMPULAN Sifat-sifat Bahan Dasar}

Tabel 1. Sifat-sifat bahan dasar

\begin{tabular}{lccc}
\hline \multicolumn{1}{c}{ Sifat } & Batu Bara & Sekam padi & Ampas tebu \\
\hline Kadar air (\%) & 14,31 & 21.18 & 9.01 \\
Kadar Abu (\%) & 2,02 & 2,67 & 20,71 \\
Kadar Karbon (\%) & 69,53 & 3,5 & 3,64 \\
Volatile Matter (\%) & 14,14 & 72,65 & 66,64 \\
Nilai Kalor (Kal/Kg) & 5289,395 & 3596,983 & 3283,797 \\
\hline
\end{tabular}

Hasil diatas mengungkap bahwa nilai kalor biomass ampas tebu dan sekam padi yang diteliti relatif masih cukup besar sehingga masih dapat dilakukan proses pembakaran. Nilai kadar karbon tertinggi dimiliki oleh batubara dan terlihat untuk biomass ampas tebu dan sekam padi memiliki kadar karbon yang lebih rendah, nilai kadar karbon ini akan memegang peranan penting dalam hal polusi udara yang ditimbulkan selama proses pembakaran.

\section{Pengaruh Variasi Jenis Pembriketan Terhadap Laju Pengurangan Massa, Laju Pembakaran dan Temperatur Biobriket.}

Efek variasi jenis pembriketan dalam pembakaran biobriket mempunyai pengaruh yang signifikan terhadap perubahan laju pembakaran dan temperatur Biobriket itu sendiri.

Dalam gambar 5, 6 dan 7 berikut dibawah, akan disajikan pengaruh variasi jenis pembriketan terhadap Laju pengurangan massa, laju pembakaran dan temperature Biobriket dalam pembakaran.

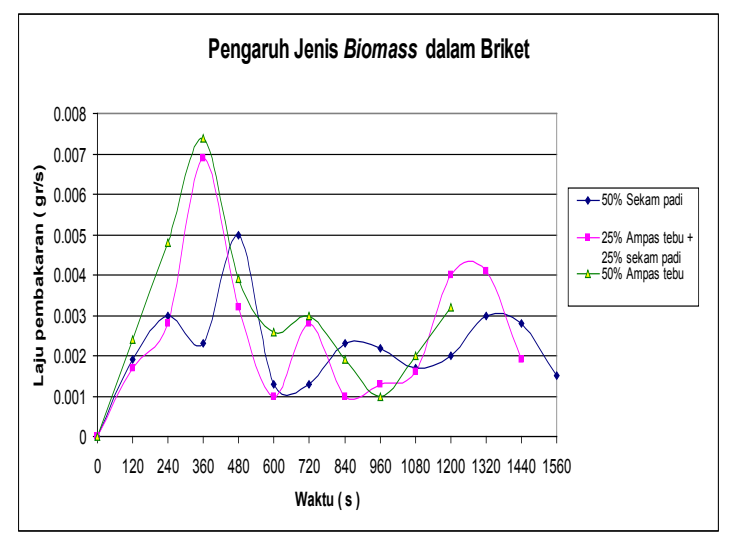

Gambar 2. Grafik pengaruh jenis pembriketan terhadap laju pengurangan massa.

Dari grafik diatas terlihat bahwa sekam padi mempunyai laju pembakaran yang rendah, sedangkan laju pembakaran yang tinggi adalah pembakaran ampas tebu, hal ini menunjukkan bahwa kandungan volatile berpengaruh terhadap laju pembakaran, namun pada biobriket campuran (sekam padi dan ampas tebu) menunjukkan laju pembakaran yang relatif tinggi. 


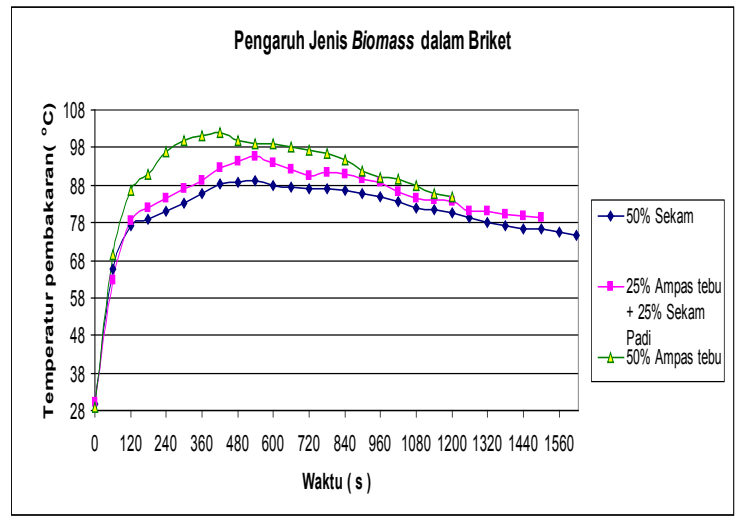

Gambar 3. Pengaruh variasi tekanan pembriketan terhadap temperature Biobriket.

Dari grafik diatas terlihat bahwa pembakaran tertinggi adalah pembakaran ampas tebu sedang sekam padi mempunyai pembakaran yang rendah, hal ini menunjukkan bahwa kandungan volatile juga sangat berpengaruh terhadap pembakaran, namun hal yang menarik terlihat pada biobriket campuran (sekam padi dan ampas tebu) yang menunjukkan pembakaran yang relatif tinggi.

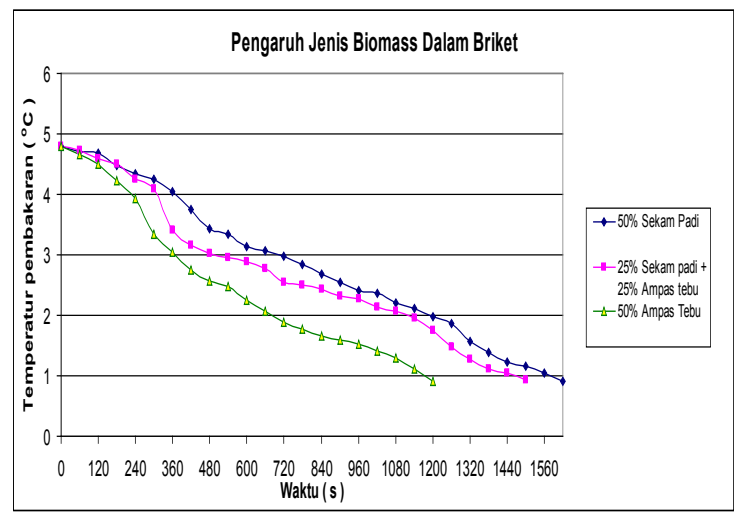

Gambar 4. Grafik pengaruh variasi jenis pembriketan terhadap laju pengurangan massa.

Dari grafik diatas terlihat bahwa penurunan massa pembakaran yang paling cepat adalah pada pembakaran ampas tebu dan yang paling lama pada sekam, sedang pencampuran antara kedua biomass menunjukkan pengurangan massa yang relatif lama.

\section{Polutan Pada Pembakaran Bahan Bakar}

Tabel 2 Polutan Pada Pembakaran Biobriket

\begin{tabular}{|l|c|c|c|}
\hline \multirow{2}{*}{\multicolumn{1}{c|}{$\begin{array}{c}\text { Jenis } \\
\text { Briket }\end{array}$}} & \multicolumn{3}{|c|}{ Jenis Polutan } \\
\cline { 2 - 4 } & HC (ppm) & CO (\%) & NO $_{\mathbf{x}}(\mathbf{\%})$ \\
\hline 50\% sekam padi & 30 & 0.004 & 0.0048 \\
\hline 50\% Ampas tebu & 110 & 0.0034 & 0.0038 \\
\hline 25\% sekam + 25\% ampas & 90 & 0.0038 & 0.0042 \\
\hline
\end{tabular}

Dari grafik didapat bahwa penambahan ampas tebu kedalam sekam padi akan mengurangi polusi yang dihasilkan. 


\section{KESIMPULAN}

1. Nilai kalor biomass ampas tebu dan sekam padi relatif tinggi sehingga masih dapat dilakukan pembakaran.

2. Penambahan ampas tebu kedalam sekam padi akan mempengaruhi karakter penurunan massa.

3. Penambahan ampas tebu kedalam sekam padi juga mempengaruhi karakter pembakaran biobriket.

4. Temperatur pembakaran tertinggi terjadi pada pembakaran biobriket campuran ampas tebu dan batubara.

5. Komposisi jenis dari biobriket sangat berpengaruh pada laju pembakaran.

6. Semakin lama laju pembakaran, temperature tertinggi yang dihasilkan semakin rendah.

7. Volatile matter sangat berpengaruh pada pembakaran briket.

8. Penambahan ampas tebu ke dalam sekam padi akan menurunkan kadar emisi $\mathrm{NO}_{\mathrm{x}}$ dan CO.

9. Sebaliknya kadar HC yang tinggi dalam briket ampas tebu akan berkurang bila ditambah sekam padi.

\section{SARAN}

1. Sebelum melakukan suatu penelitian kita harus mengontrol terlebih dahulu alat-alat yang dibutuhkan maupun yang digunakan apakah dalam kondisi layak difungsikan atau tidak. Jika ada suatu alat yang tidak berfungsi, maka segeralah untuk mencari penggantinya.

2. Pada saat melakukan suatu penelitian hendaklah kita harus hati-hati (sabar), teliti dan mempunyai etos kerja yang tinggi.

3. Bila melakukan penelitian di lain universitas, harus dapat menjaga nama almamater.

\section{DAFTAR PUSTAKA}

[1] Himawanto, D.A, 2003, "Pengolahan Limbah Pertanian menjadiBiobriket sebagai salah satu Bahan Bakar Alternatif “

[2] Naruse,I.,Gani,A.,Morishita,K.,2001,'Fundamental Characteristic on Co-Combustion of Low Rank Coal with Biomass ',Pittsburg coal Conf

[3] Saptoadi,H 2004, 'Research Of Combustion Characteristics Of Fuel Briquettes Made From Wooden Saw And Lignite.'

[4] Sudradjat,R, 2001,' The Potensial of Biomass Energy Resources in Indonesia for the Possible Development of Clean Technology Process (CPT), Jakarta

[5] Sukandarumidi,1995, 'Batubara dan gambut', UGM Pres

[6] Istanto,T 2003, 'Penelitian Pengaruh Komposisi Bahan Bakar Terhadap Laju Pembakaran Campuran Briket Batubara Dengan Sampah Ban'.

[7] Istanto,T 2003, 'Penelitian Pengaruh Kecepatan Aliran Udara Dan Temperature Udara Preheat Terhadap Laju Pembakaran Campuran Briket Batubara Dengan Sampah Ban'. 